\title{
Comunicação interna estratégica: a experiência da Embrapa
}

\author{
Strategic internal communication: \\ Embrapa's experience
}

\section{Comunicación interna estratégica: la experiencia de la Embrapa}

\section{Gilceana Galerani ${ }^{1}$ Aline Bastos ${ }^{2}$}

A comunicação interna pode ser entendida como um processo comunicacional desenvolvido por uma organização para cultivar relacionamentos qualificados, criando ou fortalecendo meios que permitam ampla participação, compartilhamento de ideias, opiniões e informações para os diferentes segmentos de público interno existentes. Tem como objetivo principal auxiliar no alcance da missão, da visão e dos objetivos estratégicos da empresa, contribuindo "para o desenvolvimento e a manutenção de um clima positivo, propício ao cumprimento das metas estratégicas da organização e ao crescimento continuado de suas atividades", como diz Gaudêncio Torquato ${ }^{3}$.

É importante também compreender que a comunicação é um "processo contínuo e permanente que permeia as interações humanas, atuando como um sistema dialógico com o objetivo de informar, persuadir, motivar e alcançar a compreensão mútua", segundo Else Lemos . Tem por objeto de trabalho pessoas que, antes de serem empregados, são cidadãos. Assim, a comunicação interna tem também por responsabilidade promover a participação e a coerência entre o discurso e a prática nas organizações. Como afirma Margarida Kunsch" , "de nada adiantarão programas maravilhosos de comunicação se os

\footnotetext{
1 É chefe da Secretaria de Comunicação (Secom) da Embrapa, em Brasília (DF). Tem mestrado em Ciências da Comunicação pela Escola de Comunicação e Artes da Universidade de São Paulo (ECA-USP), especialização em Marketing e Publicidade pela Universidade Norte do Paraná (Unopar) e graduação em Relações Públicas, pela Universidade Estadual de Londrina (UEL). É autora da obra Avaliação em comunicação organizacional (2006). Na Embrapa, exerceu anteriormente as funções de supervisora de Comunicação Empresarial, coordenadora de Comunicação Interna e assessora da diretoria executiva. E-mail: gilceana.galerani@embrapa.br.

2 É supervisora de Relacionamento com o Público Interno na Secretaria de Comunicação (Secom) da Embrapa, em Brasília (DF). Tem mestrado em Comunicação e Cultura pela Universidade Federal do Rio de Janeiro (UFRJ) e graduação em Comunicação Social - habilitação em Relações Públicas e Jornalismo pela Universidade Federal do Paraná (UFPR). Na área de comunicação, já trabalhou em multinacionais, agências de comunicação e publicidade, instituições sociais, universidades e empresas públicas. E-mail: aline.bastos@embrapa.br.

3 TORQUATO, Gaudêncio. Tratado de comunicação organizacional e política. São Paulo: Cengage Learning, 2002, p. 54

4 LEMOS, Else. Comunicação interna como diferencial em relações públicas. In: FARIAS, Luiz Alberto. Relações públicas estratégicas: técnicas, conceitos e instrumentos. São Paulo: Summus, 2011.

5 KUNSCH, Margarida M. Krohling. Planejamento de relações públicas na comunicação integrada. 4. ed. São Paulo: Summus, 2003, p. 157.
} 
empregados não forem respeitados nos seus direitos de cidadãos e nem considerados o público número um no conjunto de públicos de uma organização". Dessa forma, as estratégias de comunicação interna precisam considerar ações que permitam ouvir, informar, mobilizar e estimular a participação ativa de empregados, estagiários, fornecedores e outros públicos internos que desempenham funções a serviço de uma instituição pública ou privada. Como assegura Wilson Bueno ${ }^{6}$, "o protagonismo na comunicação interna, a elevação do funcionário à condição de sujeito, o diálogo construtivo são atributos inegociáveis de uma organização e sociedade modernas".

As ações de comunicação interna favorecem também o ajustamento organizacional e a integração interna. Essa integração pode ser vista em quatro níveis, de acordo com Analisa de Medeiros Brum: integração entre as pessoas; da pessoa com a empresa; da pessoa com as chefias; entre as áreas. Nesse sentido, as estratégias de comunicação devem se voltar para 0 alinhamento da ambiência interna, já que "os ambientes internos, alimentados por eficientes fontes de comunicação, motivamse e integram-se ao espírito organizacional, contribuindo de forma mais eficaz para a consecução das metas programadas"8.

Na Empresa Brasileira de Pesquisa Agropecuária (Embrapa), a comunicação interna foi institucionalizada em 1996, com 0 lançamento da Política de Comunicação ${ }^{9}$, e vem sendo reforçada pelos planos diretores da empresa desde então. A segunda edição desse documento, publicada em 2002 e atualmente em vigor, reforça a importância da comunicação interna e preconiza que "a relação transparente e democrática com os empregados é vital para a empresa e se instaura pela adoção de um processo de gestão que estimula o diálogo e a participação e que advoga a implementação de uma autêntica cultura de comunicação".

Na prática, o documento sinaliza que a comunicação interna parte do pressuposto de que, como parceiros, os públicos internos devem reconhecer canais que possibilitem não apenas o esclarecimento sobre os compromissos da empresa e 0 papel que cada um desempenha em prol dos objetivos organizacionais, como também o diálogo aberto e transparente entre gestores e demais empregados. Atendendo a esses princípios, a empresa está estimulando o enriquecimento de debates, promovendo maior conhecimento e empoderando seus empregados para que possam auxiliar em tomadas de decisão.

Este depoimento apresenta um breve histórico e também os avanços, as perspectivas e os desafios experimentados pela Embrapa na comunicação com seus empregados. Esse público totaliza hoje cerca de 10 mil pessoas, localizadas em todas as regiões do Brasil e em alguns países dos continentes africano, americano, asiático e europeu. Esse fato, aliado à variedade de idade, cultura, tempo de serviço na empresa e formação profissional, já demonstra a principal característica dos públicos internos da Embrapa - a ampla diversidade.

\section{A EMBRAPA}

A Empresa Brasileira de Pesquisa Agropecuária (Embrapa), instituição pública vinculada ao Ministério de Agricultura, Pecuária e Abastecimento, foi criada em 26 de abril de 1973. Sua missão é viabilizar soluções de pesquisa, desenvolvimento e inovação para a sustentabilidade da agricultura, em benefício da sociedade brasileira.

6 BUENO, Wilson. Comunicação empresarial: políticas e estratégias. São Paulo: Saraiva, 2009, P. 96.

7 BRUM, Analisa de Medeiros. Respirando endomarketing. Porto Alegre: L\&PM, 2013, p. 54.

8 TORQUATO, Gaudêncio. Op. cit., p. 122.

9 EMBRAPA. Política de comunicação. 2. ed. Brasília, DF: Embrapa, 2002. Sobre o processo de implantação da política de comunicação da Embrapa recomenda-se a leitura do artigo "Política de comunicação e gestão empresarial: a experiência da Embrapa", de Jorge Duarte e Heloiza Dias da Silva (Organicom, a. 4, n. 6, 1. sem. 2007). 
Ela atua por intermédio de dezesseis unidades administrativas localizadas em sua sede, em Brasília (DF), e 47 unidades descentralizadas (centros de pesquisa e de serviços), estando presente em quase todos os estados da federação. Coordena 0 Sistema Nacional de Pesquisa Agropecuária (SNPA), constituído por instituições públicas federais, estaduais, universidades, empresas privadas e fundações, que, de forma cooperada, executam pesquisas nas diversas áreas geográficas e nos diferentes campos do conhecimento científico.

Internacionalmente, a Embrapa mantém 78 acordos bilaterais com 56 países e 89 instituições estrangeiras para pesquisa agropecuária e transferência de tecnologia. A cooperação internacional congrega também parcerias com laboratórios nos Estados Unidos (Washington), na Europa (França, Inglaterra e Alemanha) e na Ásia (Coreia do Sul e China) para o desenvolvimento de pesquisas em tecnologias de ponta, os chamados Laboratórios no Exterior (Labex's). Com essas iniciativas, pesquisadores da Embrapa e desses outros países têm acesso às mais altas tecnologias em áreas como recursos naturais, biotecnologia, informática, agricultura de precisão etc.

$\mathrm{Na}$ esfera da transferência de tecnologia para países em desenvolvimento (Cooperação Sul-Sul) destacam-se projetos da Embrapa no continente africano (Gana, Moçambique, Mali e Senegal), no continente sul-americano (Venezuela), e na América Central e no Caribe (Panamá), voltados para o desenvolvimento agrícola dessas localidades.

\section{CARACTERIZAÇÃO GERAL DOS PÚBLICOS INTERNOS}

Em qualquer organização há sensíveis diferenças entre as pessoas que participam do ambiente de trabalho. Na Embrapa, inúmeros fatores já citados contribuem para que as diferenças sejam ainda mais marcantes, o que faz da diversidade uma das principais características do ambiente interno. Esse fato exige da comunicação o exercício diário da criatividade aliada à segmentação dos públicos internos em momentos distintos, para maior eficiência do processo comunicacional. Percebe-se, dessa forma, a pertinência do tratamento personalizado a cada grupo que se forma em momentos distintos, fortalecendo a tese da multiplicidade dos públicos - "públicos internos no plural. Muitos, muitos públicos. É assim que deve ser", como afirma Bueno ${ }^{10}$.

Dos 9.813 empregados da Embrapa, aproximadamente 25\% são pesquisadores com mestrado, doutorado ou pós-doutorado; $25 \%$, analistas com no mínimo curso superior; e $50 \%$, assistentes ou técnicos com ensino fundamental ou médio. Do total, $29,8 \%$ são mulheres e $29,5 \%$, negros ou pardos. Aproximadamente 1 mil empregados ocupam cargos de gestão de diferentes categorias. Do total de empregados, 30,82\% possuem até cinco anos de empresa, o que representa 3.024 pessoas, certamente, com expectativas e bagagem cultural diferentes das demais. A diversidade na Embrapa também é estrutural, devido às grandes diferenças existentes nos locais de instalação dos 47 centros de pesquisa, envolvendo maior ou menor facilidade para se efetivar a comunicação interna ideal.

Se, por um lado, essa diversidade favorece a criatividade, geração de ideias e inovação, representa, por outro lado, um dos maiores desafios da comunicação interna da Embrapa. Devido a essa diversidade e também às demandas crescentes, a segmentação do público interno e a priorização de programas de comunicação têm sido uma prática constante, uma vez que, segundo Bueno" "cada público deve ser visto em suas particularidades, em suas demandas, em suas expectativas, em sua forma específica de comunicação. 0 que pode ser razoável para um deles poder contraproducente para os demais". 
Para a tomada de decisão sobre o que deve ser prioritário, são consideradas situações e temáticas de menor ou maior sensibilidade para conhecimento pelos empregados, além de se analisarem os riscos para a imagem e a sustentabilidade da Embrapa e também as condições de determinado segmento interno conseguir administrar a sua comunicação em um determinado desafio. São ainda vistas como prioritárias as ações de maior emergência e, não sendo possível atender a muitas demandas importantes num mesmo período, são planejadas estratégias ou soluções para curto, médio e longo prazos.

\section{A COMUNICAÇÃO INTERNA NA EMBRAPA}

A comunicação, na Embrapa, passou a ser orientada como compromisso de todos os empregados desde a implementação da política de comunicação, em 1996. Antes disso, a comunicação era fragmentada, já que cada centro de pesquisa ordenava suas demandas e prioridades para a área. Com a ausência de um sistema integrado, havia deficiências como pouca interação entre os públicos internos - especialmente entre os centros de pesquisa -, ações com carência de planejamento e foco, comunicação entendida, na maioria das vezes, como sinônimo de divulgação, além de duplicidade de esforços e recursos financeiros diluídos em vários programas.

Com o advento da política de comunicação, todos os centros de pesquisa passaram a contar com profissionais de comunicação e a então Assessoria de Comunicação (ACS) passou a liderar a rede de comunicadores. Junto com a implantação da política, entre 1996 e 1998 houve também a mudança da marca da empresa; a alteração dos nomes de todas as unidades de pesquisa; o estabelecimento de manuais com padrões mínimos para organização de eventos, atendimento à imprensa e atendimento ao cidadão. 0 presidente de então encampou de tal forma a liderança pelas mudanças, que era o principal porta-voz e guardião dos novos conceitos e práticas. Foi uma verdadeira revolução para a comunicação da empresa e provavelmente um dos maiores passos já dados pela comunicação de uma empresa pública de âmbito federal.

Como suporte ao amplo trabalho, uma extensa e intensa campanha interna foi elaborada sob a coordenação da ACS para envolver e mobilizar os empregados de forma profunda em torno da ideia de que "a comunicação é responsabilidade de todos". Até hoje (2013), comenta-se na instituição a efetividade do trabalho realizado internamente naquele período.

Alguns anos após a campanha, a Embrapa passou por momentos de restrições orçamentárias, o que implicou menores possibilidades para capacitação e contratação de empregados e certa desaceleração das atividades de comunicação interna. Entretanto, nos planos diretores da empresa, evidenciava-se cada vez mais a necessidade de voltar a fortalecê-la e a fazer jus ao desafio de integrar um público interno tão diverso e, ao mesmo tempo, tão comprometido com a gestão do conhecimento científico.

Por volta de 2005, a comunicação interna foi inserida no organograma da Assessoria de Comunicação Social como uma coordenadoria, com equipe própria na liderança da atividade para a empresa como um todo. Foram então desenvolvidos instrumentos de pesquisa, táticas de interação entre unidades com a criação de facilitadores de comunicação interna em cada uma delas. Também foram impulsionadas campanhas e ferramentas de divulgação e promoveu-se maior integração e parceria com o Departamento de Gestão de Pessoas, o que gerou diversos avanços comprovados em avaliações de clima organizacional. Foi um momento de fortalecimento da comunicação interna, com o apoio irrestrito do presidente da Embrapa à época, que chegou a prestar depoimento sobre a importância do assunto, reproduzido por Duarte e Silva12.

12 DUARTE, Jorge; SILVA, Heloiza Dias da. Op. cit., p. 24. 
O nosso grande desafio é melhorar a comunicação interna da empresa. Essa área é cada vez mais importante para as instituições que geram conhecimento como a Embrapa e que têm como maior capital os seus recursos humanos, os seus empregados. (...) É preciso entender que há dois tipos de conhecimento: o explícito, que é aquele que podemos quantificar, [gerando] relatórios e avaliações formais, e o conhecimento tácito, que é aquele que está na cabeça, no coração e nas emoções das pessoas, e que foram adquiridos ao longo de suas experiências pessoais e profissionais. A estratégia fundamental de toda organização de C\&T e inovação é mobilizar e estimular os seus empregados a contribuir não apenas com o conhecimento explícito, mas, e principalmente, com o conhecimento tácito. E isso não se faz sem comunicação.

\section{A situação atual da comunicação interna}

A comunicação na Embrapa está contemplada no V Plano Diretor da Embrapa (PDE) ${ }^{13}$, documento programático de nível estratégico, que define seu âmbito de atuação. 0 PDE registra desafios e estratégias de médio e de longo prazos, com objetivo de garantir o cumprimento da missão institucional e a sustentabilidade da organização.

Como um dos desafios organizacionais e institucionais no V PDE está definido "fortalecer a comunicação institucional e mercadológica para atuar estrategicamente diante dos desafios da sociedade da informação". E, dentre as estratégias associadas ou linhas de ação vinculadas a essa grande diretriz, destaca-se "promover ações e produtos que integrem a comunicação interna, com o intuito de criar um ambiente cooperativo e de livre circulação de ideias", o que, por sua vez, comporta como subestratégias:

- desenvolver ações de monitoramento das percepções do público interno;

- desenvolver mecanismos de comunicação que estimulem a participação e o empenho dos empregados nos programas conduzidos pela empresa;

• estimular fluxos de comunicação que promovam a interação entre dirigentes, empregados e unidades;

- promover maior integração entre as equipes de comunicação na sede e nas unidades descentralizadas.

0 documento Política de comunicação, de 2002, registra a criação e manutenção de fluxos de comunicação que facilitem a interação entre a Embrapa e seus públicos estratégicos, num processo de influência recíproca. A comunicação tem sido pensada de forma integrada e exercida a partir de seus focos (institucional e mercadológico) e espaços prioritários (comunicação com os empregados, com o governo, com a sociedade etc.). "É comandada por uma diretriz única, que exibe valores e conceitos compartilhados por toda a organização"14.

A gestão da comunicação da Embrapa, inclusive da comunicação interna, está sob a liderança da atual Secretaria de Comunicação (Secom), unidade administrativa centralizada e subordinada ao presidente da empresa. Todos os centros de pesquisa possuem um Núcleo de Comunicação Organizacional (NCO), vinculado à chefia-geral da unidade. Os NCOs são responsáveis pela execução local das ações corporativas presentes no Plano Integrado de Comunicação (PIC), cuja elaboração é liderada pela Secom, além de realizarem ações necessárias à sua realidade regional. Para isso, os NCOs e a Secom contam atualmente com 181 profissionais de comunicação, sendo 111 jornalistas, 55 relações-públicas, quinze publicitários, além de outros dezessete profissionais ligados às áreas de fotografia, design, rádio e tv. 
A interação entre os comunicadores da Embrapa foi potencializada em 2012 com a implantação de uma comunidade virtual interna, denominada Rede.com. Esse espaço permite o compartilhamento de orientações da Secom, debates em fóruns específicos, divulgação de boas práticas dos centros de pesquisas, disseminação de informações sobre cursos e congressos da área, publicações acadêmicas, entre outros itens. Hoje, é o principal canal de compartilhamento de informações, diálogo e interação entre os profissionais de comunicação por todo o país.

Desde 2010, a Secretaria de Comunicação elabora e executa um planejamento anual, em conjunto com todas as unidades, que resulta no Plano Integrado de Comunicação (PIC). Estratégias, ações e metas são definidas a partir de problemas e desafios de comunicação identificados nas pesquisas de clima organizacional, de opinião e de imagem com públicos estratégicos, que podem ser complementadas por diretrizes da gestão superior e por questões locais apresentadas pelos supervisores dos núcleos de comunicação organizacional de todo o país.

As questões desafiadoras e inovadoras na área de comunicação podem integrar projetos e arranjos do Sistema Embrapa de Gestão (SEG), o principal instrumento norteador e financiador de iniciativas nos três pilares do processo de produção da empresa: pesquisa \& desenvolvimento; transferência de tecnologia; e administração. Atualmente, há onze projetos relacionados à comunicação interna em andamento na carteira do Macroprograma 4, específico para estratégias e ações inovadoras de comunicação e transferência de tecnologia. Além disso, um novo arranjo de projetos está em elaboração em conjunto com mais de dez unidades, com vistas à superação de desafios estratégicos de comunicação, especialmente para o fortalecimento e monitoramento de fluxos, canais e/ou espaços de interação com os empregados da Embrapa.

\section{Diagnóstico da comunicação interna}

Em 2012, foi realizado um diagnóstico de comunicação interna por uma consultoria que teve como subsídios pesquisas de opinião realizadas nos últimos anos, dirigidas a supervisores dos núcleos de comunicação (NCOs), gestores e demais empregados: pesquisa de cultura organizacional (2010); e avaliação dos veículos internos de comunicação (2010); sondagem de comunicação interna (2011); pesquisa de clima organizacional e qualidade de vida no trabalho - QVT (2011); pesquisa de imagem (2012); e diagnóstico sobre as intranets da Embrapa (2012).

O diagnóstico identificou pontos que são indícios da necessidade de melhoria do processo de comunicação interna e de sua adequação às novas exigências da Embrapa, às estratégias corporativas e ao novo perfil dos empregados da empresa. Alguns desafios identificados não estão sob a alçada exclusiva da comunicação, mas sim relacionados à governança e à gestão de uma forma ampla, porém com impacto direto nos processos de comunicação interna. Apresenta-se no diagnóstico, principalmente, a necessidade de promover ações para alinhamento estratégico entre a organização e seus empregados nos diversos segmentos.

O diagnóstico foi inserido entre os subsídios que conduzem a atualização da Política de Comunicação. 0 documento também orientou a elaboração de um Programa Corporativo de Comunicação Interna, inserido ao Plano Integrado de Comunicação (PIC) da Embrapa para 2013.

Como principal objetivo, o Programa Corporativo de Comunicação Interna se propõe promover o alinhamento estratégico de forma a fortalecer os relacionamentos internos, promover o diálogo, a circulação ágil de informações, a cooperação e a interação entre os vários segmentos de empregados da Embrapa. Esse programa está em consonância com a atual filosofia 
de trabalho da Secretaria de Comunicação (Secom) para a comunicação interna, baseando-se em cinco conceitos-chaves: transparência; agilidade; cooperação, articulação; e qualidade.

O programa prevê ações a serem executadas e avaliadas em curto, médio e longo prazos, em parceria com o Departamento de Gestão de Pessoas (DGP). Em curto prazo, foram priorizadas ações de comunicação para os seguintes segmentos do público interno:

- empregados em geral;

- gestores;

- empregados em trabalho externo às instalações da Embrapa (no exterior; em outras instituições públicas por razão de cessão; e em estudos de pós-graduação);

- empregados cujo trabalho não prevê acesso a computador e/ou à internet;

- empregados da sede da Empresa, em Brasília.

Estratégias e ações delineadas também almejam atingir os objetivos específicos a seguir detalhados:

• contribuir para maior agilidade e transparência no atendimento às demandas internas por informação;

- ampliar o apoio dos profissionais de comunicação aos gestores da empresa;

- estabelecer agenda periódica de comunicação face a face entre gestores e empregados (reuniões gerais, visitas às instalações de trabalho etc.);

- ampliar articulação entre núcleos de comunicação das unidades e a Secom para otimizar a aplicação de recursos em ações corporativas de comunicação interna;

- favorecer e estimular o compartilhamento de ideias e informações dentro da empresa, estimulando atitudes de "espírito" cooperativo;

- incentivar e criar fluxos e canais de informação para empregados com acesso reduzido a informações corporativas empregados de campo, casas de vegetação, manutenção, laboratórios, escritórios externos, inclusive no exterior;

- apresentar aos empregados desafios, êxitos e contribuições da Embrapa para a sociedade, com vistas a reforçar 0 sentimento de orgulho pela empresa que ele ajuda a construir;

- estimular os gestores e o público interno a entenderem a importância de sua atuação no processo de comunicação interna;

- melhorar a expertise dos gestores em comunicação interna. 
Para o alcance dos objetivos esperados foram delineados cinco projetos, cujas principais atividades estão apresentadas na Tabela 1.

Tabela 1 - Resumo do programa de comunicação interna para a Embrapa.

PROJETO CORPORATIVO
(EMPREGADOS EM GERAL)
$\begin{array}{r}\text { Monitoramento do ambiente interno por meio de articuladores de comunicação interna } \\ \text { nomeados em todas as unidades centrais e descentralizadas. }\end{array}$
Melhorias nos veículos e canais de comunicação interna: Folha da Embrapa, Todos.com,
Mensagem da diretoria executiva, Nova intranet corporativa, Plataforma de comunicação instantânea,
Murais digitais e Anúncios digitais corporativos.

Ações de relacionamento com empregados: campanhas em datas comemorativas;

videoconferências bimestrais com a diretoria-executiva; reuniões gerais bimestrais com chefias nas unidades descentralizadas; cumprimentos da diretoria-executiva em ocasiões especiais na vida profissional do empregado.

\section{PROJETO GESTORES}

Desenvolvimento de veículos de comunicação interna específicos para gestores: criação da Sala de Gestores (ambiente virtual colaborativo); reformulação do veículo Diretoria Informa.

Apoio à gestão: aplicativo para comunicação direta e instantânea para smartphones e tablets; guia de mensagens (orientações estratégicas para posicionamento público de gestores); documento Princípios de

Gestão (orientações básicas para novos gestores); capacitação em comunicação interna e face a face.

\section{PROJETO EMPREGADOS LOTADOS EM INSTALAÇÕES EXTERNAS}

Empregados no exterior: criação de fórum na nova intranet; consultas periódicas para auxiliar em decisões de comunicação; reformulação de informativo. Ações a serem desenvolvidas em parceria com a Secretaria de Relações Internacionais.

Empregados cedidos e em pós-graduação: criação de banco de dados; reuniões anuais da diretoria-executiva com pós-graduandos; envio de informativos e outros documentos institucionais; espaço interativo na nova intranet corporativa.

\section{PROJETO EMPREGADOS SEM ACESSO FUNCIONAL À INTERNET}

Encontros presenciais periódicos: visita de gestores às instalações, em especial a campos experimentais, casas de vegetação, área de manutenção etc., para breves diálogos com empregados.

\section{PROJETO EMPREGADOS DO PARQUE ESTAÇÃO BIOLÓGICA (BRASÍLIA)}

Nomeação dos articuladores de comunicação interna em cada unidade central.

Criação e manutenção de novos veículos de comunicação interna: murais digitais, sistema de som, jornal de parede.

Sinalização e padronização visual do edifício-sede.

Gestão e divulgação de agenda de eventos organizados ou apoiados pela Embrapa e em execução no Parque Estação Biológica. 
Dessas ações destaca-se o monitoramento do ambiente interno, a ser realizado pela Secretaria de Comunicação (Secom) em parceria com os articuladores de comunicação interna das unidades centrais e descentralizadas, para administrar informações que impactam na comunicação interna e na imagem da empresa e possam ser úteis ao planejamento e para ações emergenciais de comunicação. A proposta é atuar numa efetiva rede de pessoas que possam representar o seu local de trabalho e contribuir para providências ágeis ou estratégicas para a melhoria da comunicação interna. Como afirma Flávio Schmidt15, "com as redes você assegura a conscientização, o engajamento e garante a contribuição efetiva de cada um no processo de desenvolvimento e resultados de comunicação interna".

Os veículos e canais de comunicação interna também serão aprimorados. Com a expansão da internet e dos veículos de comunicação eletrônica e digital, há uma expectativa para a expansão das modalidades de comunicação interativa colaborativa, que possibilitam participação ativa do receptor. Atualmente, a Embrapa possui os seguintes veículos de comunicação interna corporativos:

Tabela 2 - Veículos de comunicação interna da Embrapa.

\begin{tabular}{|c|c|}
\hline Veículos de comunicação interna corporativos & Características \\
\hline Folha da Embrapa & $\begin{array}{l}\text { Veículo impresso com periodicidade mensal, } \\
\text { enviado para a residência de todos os empregados } \\
\text { ativos e inativos (aposentados) da Embrapa. } \\
\text { Disponível também em versão digital na intranet. }\end{array}$ \\
\hline Todos.com & $\begin{array}{l}\text { Informativo eletrônico com periodicidade semanal, } \\
\text { enviado para o e-mail de todos os empregados. }\end{array}$ \\
\hline Mensagem da diretoria-executiva & $\begin{array}{l}\text { Veículo para comunicação direta da diretoria-exe- } \\
\text { çutiva com os empregados em momentos especiais. } \\
\text { É enviada por e-mail a todos os empregados. }\end{array}$ \\
\hline Intranet corporativa & $\begin{array}{l}\text { Ambiente digital em reformulação. A nova versão } \\
\text { reunirá, a partir de 2014, informações de todas as } \\
\text { unidades com recursos de apoio a gestão de pessoas } \\
\text { (auxílio ao mapeamento de competências) e de } \\
\text { colaboração e interação. }\end{array}$ \\
\hline Mural digital & $\begin{array}{l}\text { Veículo digital em monitores nas instalações da } \\
\text { Embrapa, com atualização diária. Projeto-piloto } \\
\text { em andamento na sede da empresa. }\end{array}$ \\
\hline $\begin{array}{l}\text { Plataforma de comunicação instantânea } \\
\text { (em processo de implantação) }\end{array}$ & $\begin{array}{l}\text { Plataforma digital de comunicação corporativa para } \\
\text { envio de alertas informativos para desktops, notebooks } \\
\text { ou telefones celulares. As mensagens são veiculadas } \\
\text { em formato de texto, imagem, boletim, vídeo, screensaver } \\
\text { dinâmico, superalerta, enquete ou SMS. O veículo permite } \\
\text { enviar mensagens de forma instantânea a todos os } \\
\text { empregados com acesso à internet. }\end{array}$ \\
\hline
\end{tabular}

Para 2014, está prevista a atualização do Manual gráfico e editorial dos veículos de comunicação interna, atendendo a uma expectativa apontada no diagnóstico de comunicação interna. As diretrizes decorrentes desse trabalho serão incorporadas nos veículos corporativos e estes poderão servir de modelo para as unidades descentralizadas.

Como aliadas dos veículos e canais de comunicação interna, são realizadas e serão fortalecidas diversas campanhas e ações de relacionamento com empregados. Há dois anos foi estabelecido, em parceria o Departamento de Gestão de Pessoas (DGP), um calendário interno com as principais datas comemorativas do ano. Nessas datas, são elaborados anúncios eletrônicos 
corporativos e matérias jornalísticas com pautas temáticas, tendo como personagens os próprios empregados contando suas histórias. É uma ação que vem gerando manifestações positivas e somente se viabiliza por haver forte envolvimento dos núcleos de comunicação organizacional das unidades descentralizadas da Embrapa.

Entretanto, o grande esforço da nova gestão da Secretaria de Comunicação está voltado para o fortalecimento da comunicação para entre lideranças. Em maio de 2013 foi criada a Sala de Gestores, ambiente colaborativo para troca de informações exclusivas e diálogo entre a diretoria-executiva e gestores da alta administração das unidades centrais e das descentralizadas. 0 Departamento de Gestão de Pessoas também deve contemplar os gestores de forma prioritária em seus projetos de capacitação, especialmente aqueles de reforço das competências necessárias para a condução da comunicação gerencial e face a face por chefes-gerais e adjuntos, coordenadores e supervisores.

De forma complementar a um plano de relacionamento elaborado pela Secom, a diretoria-executiva vem incentivando os gestores a realizarem reuniões gerais periódicas (mensal/ bimestral) com empregados de suas unidades, com pauta aberta e pré-definida e avaliação de resultados. 0 objetivo é criar um ambiente propício para participação, debate, diálogo, troca de ideias e informações entre o gestor e os empregados das unidades, sem temer o contraditório. Acredita-se que essa iniciativa sistematizada possibilite amplo avanço no processo dialógico dentro da empresa e promova o tratamento transparente de questões importantes para o público interno. Seguindo os princípios da teoria da complexidade, de Edgar Morin ${ }^{16}$, contradições não são catástrofes, "mas representam características naturais a todos os processos e devem ser trabalhadas para que sejam promovidas as transformações e as ações necessárias”, de acordo com Juliana Ramos ${ }^{17}$.

Seguindo o mesmo princípio da valorização da comunicação face a face, também vem sendo estimuladas visitas dos gestores ao local de trabalho dos empregados, principalmente a laboratórios, campos experimentais, casas de vegetação e setores de manutenção, que congregam empregados com menor acesso à informação eletrônica instantânea, para comunicação direta sobre assuntos estratégicos de interesse comum entre empresa e públicos internos.

\section{Desafios e perspectivas}

A comunicação interna realizada na Embrapa tem avançado ao longo dos anos, mas apresenta hoje um desafio importante a ser tratado. No momento em que a empresa completa seus quarenta anos, trabalha fortemente na antecipação de cenários e na antevisão de seus desafios. Há em curso, ainda, uma renovação do quadro funcional e estão previstas mudanças substanciais para permitir que a organização esteja preparada para responder às demandas complexas dos próximos vinte anos. Vê-se, portanto, a necessidade de fortalecer o alinhamento estratégico da comunicação interna aos objetivos e às diretrizes organizacionais sob essa nova ótica, preparando também as pessoas para os desafios que estão batendo à porta.

Para atender a essa demanda, a Secom já trabalha com a ampliação do Programa Corporativo de Comunicação Interna, orientando-o para o cidadão presente na organização, que está cada vez mais crítico e plenamente informado sobre 0 mundo por meio das redes e suas inúmeras fontes de conhecimento. Esse programa deverá seguir as mesmas inferências apresentadas por Else Lemos em suas investigações sobre estratégias contemporâneas para a comunicação interna. No contexto dessas reflexões, o programa terá como principais alicerces o estudo da cultura organizacional afetada por processo em ajustes e as perspectivas para a organização nos próximos anos, assim como a necessidade de intenso envolvimento dos 
gestores com o planejamento e a disseminação das mensagens. Objetiva-se, por meio dessa filosofia, maior engajamento e comprometimento dos empregados frente a metas organizacionais; lideranças incentivadas a aumentar sua participação no processo de comunicação; ampliação do diálogo e da interação entre os vários segmentos do público interno da Embrapa; "dar a voz" e contribuir para maior enriquecimento e alcance de objetivos dos empregados.

Fundamentado nesses princípios, esse programa poderá fortalecer ainda mais o processo de comunicação interna, integrando algumas iniciativas até então realizadas de forma isolada nas unidades descentralizadas. Por conter projetos de diversas unidades, contemplará vários saberes e culturas, o que enriquecerá o escopo da comunicação, ajustando-a ao princípio do "respeitar às diferenças e cultivar as semelhanças"18.

Esse novo instrumento de planejamento em elaboração envolve dez projetos de diferentes unidades e é coordenado pela Secom. Contém ações para incentivar a compreensão das diretrizes institucionais; capacitar os gestores em comunicação interna, especialmente face a face, qualificando-os a ouvir as demandas de suas equipes e a transmitir informações relevantes para o crescimento profissional e o melhor desempenho das atividades programadas; intensificar os fluxos de informação internos e ampliar os espaços de troca de informações que geram valor para os empregados, respeitando suas características e a diversidade de perfis e oferecendo-lhes condições de se sentirem parte integrante da organização e de atuar como disseminadores da marca Embrapa. Em resumo, estará orientado a assegurar condições para que o empregado amplie sua relação de confiança com a empresa e a ajude a caminhar nos seus próximos vinte anos, ciente de que uma empresa fortalecida garantirá trabalhadores também fortalecidos.

\section{CONSIDERAÇÕES FINAIS}

Não é raro ouvir que, em instituições públicas, a comunicação normalmente encontra barreiras relativas à descontinuidade dos processos e à dificuldade na obtenção de recursos orçamentários e financeiros para executar projetos e até atividades de rotina. Em que pese acreditar que essa não é mais a realidade em grande parcela das empresas governamentais, destacase também que, para desenvolver comunicação interna eficiente, é preciso ir além de recursos e processos continuados.

Atualmente, é fundamental o estabelecimento de um processo que permita atenção às características que diferenciam uma organização de outra, e na maioria das vezes o diferencial está nas pessoas que integram a instituição e na própria cultura organizacional. As empresas públicas já perceberam isso e passaram a estar mais atentas a estratégias de comunicação que as auxiliem a buscar a harmonia nos relacionamentos internos e façam com que os empregados ou servidores compreendam a necessidade de serem parceiros da gestão.

É o caso da Embrapa, que tem a comunicação interna como item estratégico em seu processo de planejamento. Dotada de ampla diversidade interna, a empresa registra a importância da comunicação com empregados em seus planos diretores e em sua política de comunicação, tendo dado exemplos do quanto busca a excelência no relacionamento com pesquisadores, analistas, técnicos e assistentes, as quatro categorias funcionais nela existentes.

Aempresa tem evoluído nessaárea, sendo prova dessa afirmativa o amplo envolvimento interno que conseguiu nas estratégias de comemoração de seu quadragésimo aniversário, comemorado desde abril de 2013 e programado para se encerrar em 
abril de 2014 ${ }^{19}$. Para a Secretaria de Comunicação da Embrapa, responsável pela gestão de sua comunicação, as iniciativas de maior êxito são aquelas que promovem o diálogo e dão a voz aos empregados, seja em videoconferências e reuniões interativas ou em simples consulta para ouvir opiniões. Esse fato também demonstra que uma cultura de comunicação não está muito longe e que a natureza da organização - ciência e tecnologia - pode ter sido importante aliada em estratégias de promoção do diálogo e do debate sobre o contraditório e em favor de resultados seguros na tomada de decisão.

Os avanços já conquistados demandam uma atuação ainda mais estratégica da comunicação interna. 0 futuro está sendo mapeado e a Embrapa quer antecipar respostas para os problemas e desafios que virão. Os públicos internos podem compreender e compor o esforço pela gestão antecipada e estratégica da ciência agropecuária do futuro. E a comunicação interna terá de ajudar nesse intento.

A Secretaria de Comunicação, como facilitadora desse processo, trabalhará com sua rede especialmente na capacitação de gestores e no maior apoio a eles; na promoção de novos canais e instrumentos de comunicação; no incentivo ao monitoramento constante do ambiente para que seja possível minimizar riscos e agir mais rapidamente em situações sensíveis; na valorização do fator humano na organização, sempre em parceria com as áreas de gestão de pessoas. Como pregaram os pioneiros da comunicação na Embrapa, "a comunicação é responsabilidade de todos", e essa verdade pode ser assegurada por meio do alinhamento no tratamento dos assuntos corporativos. 